\title{
It Takes Two to Tango - Climate Policy at COP 10 in Buenos Aires and Beyond
}

\author{
Hermann E. Ott, Bernd Brouns, Wolfgang Sterk and Bettina Wittneben*
}

\section{Introduction}

Positive moments in international climate diplomacy generally do not last very long. On 18 November 2004, Russia finally completed its ratification of the Kyoto Protocol to the United Nations Framework Convention on Climate Change (UNFCCC). In accordance with Article 25.1, Russia's ratification was the last one needed for the Protocol to enter into force, which took place amid worldwide celebrations on 16 February 2005. International climate policy has thus entered into a new era: For the first time, industrialised countries are legally committed to reducing their overall greenhouse gas emissions.

It was against this background that the roth Conference of the Parties (COP) to the UNFCCC convened in Buenos Aires from 6 to 17 December 2004 with more than 6000 participants. And at first the good news did not stop there. Almost simultaneously with Russia, Nigeria had also announced its ratification of the Protocol. Because Nigeria is a member of the Organisation of Petroleum Exporting Countries (OPEC) and one of the most populous countries in the world, its ratification was of considerable strategic significance. Other countries - among them Indonesia - announced their ratification as well, raising the total number of Parties to $132^{1}$. In addition, on the first day of the COP, Canada dropped its demand to be accorded a special emission discount for its export of hydro energy to the United States, which had consumed considerable energy in the negotiations for some time ${ }^{2}$.

One could have expected the EU to be in a jubilant mood at this COP. After all, it was mainly due to the Union's persistent efforts that the Kyoto Protocol prevailed, after the newly elected Bush administration had voiced its opposition in early 2001 . Its entry into force is therefore a major "soft power" policy achievement of the EU. Nevertheless, after brief signs of enthusiasm by representatives of the EU delegations and the UN secretariat, it was left to members of the Climate Action Network of non-governmental organisations (and some Ministers like German Environment Minister Jürgen Trittin) to celebrate the forthcoming entry into force of the Protocol. The conference very quickly moved back into its familiar habit of struggling over technical details and worrying about the future of the regime. As the representative of the US clarified right at the beginning, the administration of President Bush would not change its negative attitude towards the Protocol and considered discussions about the future of the regime "premature". Instead, the strategy of the United States continues to focus on technology initiatives (e.g. carbon capture and sequestration and hydrogen technologies) as well as operating under bilateral agreements rather than a broad multilateral process.

In the multilateral arena of COP 10, the re-elected Bush administration, accompanied by its traditional ally Saudi Arabia, resumed its unhelpful role. The conference had barely opened, when the US proposed to delete agenda items which envisaged input from the UNFCCC to the upcoming 10-year review of the Barbados Programme of Action for the Sustainable Development of Small Island Developing States, to the World Conference on Disaster Reduction, and to the fourteenth meeting of the United Nations Commission on Sustainable Development, which will focus on energy ${ }^{3}$. The motivation behind this move may have been to prevent recognition of the possible impacts of cli-

\footnotetext{
* The authors all work for the Wuppertal Institute for Climate, Environment and Energy.

1 At the writing of this article in March 2005, 146 Parties had ratified the Kyoto Protocol.

2 Draft report of the Conference of the Parties on its tenth session, FCCC/CP/2004/L.1, 13 December 2004. The final version of the COP report was not yet finalized by the UNFCCC secretariat up to 26 March 2005. For this reason, the quoted COP decisions have only preliminary references. As of 26 March all COP decisions are available in an advance unedited version at the UNFCCC-website:

http://unfccc.int/meetings/cop_10/items/2944.php.

3 lbid.
} 
mate change in other fora. The US delegation also attempted to replace the words "climate change" each time they appeared in a document with the vague term "climate variability".

The question of "how to deal with the US" was thus once again one of the key concerns at this conference. The European Union made a rather futile attempt to "dance" with the United States in Buenos Aires, soon realizing that it takes two to tango. The main arena for this attempt was a rather innocent issue, namely the question of whether to organise seminars to discuss future directions of the regime. This issue is explored next, followed by an analysis of the decisions taken on adaptation and the Clean Development Mechanism as well as of other decisions. The article concludes with an outlook on international climate policy in the years to come.

\section{Pathways into the future}

How to chart the way forward after 2012 loomed large in Buenos Aires. Aside from the substantive issues, namely the design, scope and extent of future targets, the forum for negotiations is of some importance. There are in principle two possibilities: Negotiations could take place within the framework of the Convention's COP or within the framework of the future Conferences of the Parties serving as the Meeting of the Parties to the Kyoto Protocol (COP/MOP). In the latter, the US and other countries that have not yet ratified the Kyoto Protocol would be able to attend as observers, but without the right to vote. Negotiating within the COP process, on the other hand, would include the US as fully-fledged party, which many States would favour in order to ensure its presence in any future process. However, this would also provide the US with a veto that, as matters currently stand, could render a constructive process more difficult. This issue was a major topic in informal discussions even though it will not be formally deliberated until COP 11 and COP/MOP 1 (November/December 2005).

A faint tectonic trembling as a warning of the eruptions to come could already be felt at COP 10. The question of how to initiate talks on the future of the regime revolved around a proposal circulated

4 The decisive role of Raul Estrada-Oyuela during negotiations at COP 3 is described in Oberthür/Ott, The Kyoto Protocol. International Climate Policy for the 21st Century, 1999, pp. 77-91. by Argentina to conduct two seminars in 2005 aimed at an exchange of views in preparation for the future negotiations on the post-2012 period. However, this seemingly innocent proposal, termed by the Dutch lead negotiator "talks about talks about talks", was heavily opposed by the US and Saudi Arabia. At the start of the second week, the US informally circulated a "Draft text of a seminar decision the US could accept" according to which there would have been only one seminar, which would have provided a forum for discussion only about past activities. In addition, their proposal explicitly excluded any reporting back to COP 11, which would have ensured a one-off event without any follow-up.

Initially, many developing countries, which usually aim to present a united front in the so-called Group of 77 and China (G-77 and China), were also sceptical about the proposed seminars. They were concerned that they could lead to an early debate about new developing country commitments even before industrialised countries had to implement theirs. Referring to industrialised countries' historical responsibility for global warming and pointing out that meeting their development needs will necessarily increase their greenhouse gas emissions, they have so far always strongly rejected such proposals. Especially Brazil, China and India, and thus almost all of the leading developing countries, were opposed to the seminars. It was therefore left to the EU to champion the seminars, with some aid from the Alliance of Small Island States (AOSIS), which, due to rising sea levels, will be among those worst hit by climate change.

Things were further complicated when Raúl Estrada-Oyuela, the Argentine "father of the Kyoto Protocol" ${ }^{4}$ and in Buenos Aires adviser to the president of the COP, decided to directly link the issue of the seminars to other critical negotiations on adaptation and financing. This package was negotiated during the last days in a small group of high-level negotiators chaired by Estrada. The deliberations behind closed doors continued after the supposed close of the conference into the early morning hours of the weekend without coming to an agreement. The decision on the seminars was only reached after an exhausting discussion in plenary combined with (again) informal consultations during sunrise of Saturday morning.

As adopted, the decision was rather weak and did in many respects resemble the informal pro- 
posal by the United States: Only one seminar will take place back-to-back to the meeting of Subsidiary

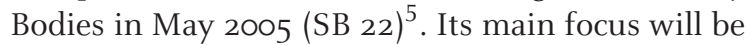
the exchange of information on existing policies and measures. The intention is clearly not to feed new policy options into the process, as the text starts by affirming that the seminar is to be conducted "without prejudice to any future negotiations, commitments, processes, frameworks or mandate under the UNFCCC and the Kyoto Protocol $^{\prime \prime}$. Furthermore, the seminar does not have a clear mandate to provide guidance to the UNFCCC process apart from making the proceedings "available to Parties (...) for their consideration, bearing in mind that this seminar does not open any negotiations leading to new commitments" ${ }^{\prime 7}$.

Discussions on future policy options are not explicitly prohibited, however. A phrase derived from the "Delhi Ministerial Declaration on Climate Change and Sustainable Development" ${ }^{8}$ adopted at COP 8 even opens a window for interpretation, namely to "promote an informal exchange of information on actions relating to mitigation and adaptation to assist Parties to continue to develop effective and appropriate responses to climate change".

\section{Assisting developing countries in their adaptation efforts}

The question of how to help developing countries adapt to the adverse impacts of climate change has been gaining in prominence over the past years and was intended to be at the forefront of COP 10. Southern delegates constantly highlighted the urgency of action and the conference was sometimes unofficially dubbed the "Adaptation COP“. The concern about climate impacts was not only confirmed by eye-witness accounts of representatives of indigenous communities, but also by in-depth, longterm scientific reports such as the Arctic Climate Impact Assessment ${ }^{9}$, which attested to the fact that global warming impacts are already being felt across the world today. The latter study demonstrates that the extent of the sea ice in the Arctic basin has decreased by $10 \%$ and the thickness by $40 \%$ between 1979 and 2003. The researchers emphasise that this development has already had detrimental impacts on human health, food security and culture in the region. This underlines the urgent need for decisions on how adaptation efforts can be facilita- ted in developing countries, as they are the most vulnerable to climate change.

However, Article 4.8 UNFCCC, the basis for negotiations on adaptation measures, refers not only to the needs and concerns of developing countries most vulnerable to the impacts of climate change but also to the adverse effects that climate protection measures might have on oil-dependent/exporting countries. Saudi Arabia and other countries from the Organisation of the Petroleum Exporting Countries (OPEC) therefore insisted on including in any relevant decision a reference to the impacts that measures to reduce emissions ("adverse impacts of response measures ${ }^{110}$ ) have on oilexporting countries. OPEC countries thus demand assistance in diversifying the structure of their economies as well as compensation for their lost export revenue due to decreased oil consumption in the industrialised countries. Coupling this demand with the adaptation needs of poor countries has effectively forestalled negotiations for a long time, since providing funds for the rich oil-exporting countries is unacceptable for most EU Member States.

Already at COP 9 this linking of issues had precluded an agreement on urgently needed financing for Least Developed Countries ${ }^{11}$. Owing to the persistence of Saudi Arabia and the United States to maintain the link between adaptation and the impact of response measures and aided by the COP President's decision to couple the negotiations of adaptation with the negotiations on the seminars, the "Buenos Aires programme of work on adaptation and response measures"12 was only adopted in

5 The seminar will take place on 16 and 17 May 2005 in Bonn. Information Note of the UNFCCC Secretariat, ICA/INF/FEB/05, 16 February 2005.

6 Decision -/CP.10, Seminar of Governmental Experts (SOGE), advance unedited version.

7 lbid.

8 Decision 1/CP.8, Delhi Ministerial Declaration on Climate Change and Sustainable Development, FCCC/CP/2002/7/Add.1, 28 March 2003.

9 Arctic Council, Impacts of a Warming Arctic - Arctic Climate Impact Assessment, Cambridge 2004.

10 This term is used in Article 4.8 UNFCCC and Article 3.14 of the Kyoto Protocol.

11 Ott/Santarius, "Developments in International and European Climate Policy in 2003", available at: http://www.wupperinst.org/COP10/index.html.

12 Decision 1/CP.10, Buenos Aires programme of work on adaptation and response measures, advance unedited version. 
the early morning hours of the weekend - albeit without the decisions on financing activities.

This decision reaffirms the need to implement previous COP decisions (esp. decision $5 / \mathrm{CP} .7^{13}$ ) on supporting adaptation efforts to avert negative impacts of climate change. The measures listed include urging industrialized countries to provide financial resources, improving information exchange and data availability, advancing vulnerability studies and adaptation projects, as well as regular reporting by the GEF on adaptation activities. In addition, three regional workshops on adaptation and one expert meeting for Small Island Developing States (SIDS) will be conducted before November 2007. OPEC Parties successfully included a section on the impact of the implementation of response measures. Although many of their demands had been compromised, the section still includes requests for funding two expert meetings and reporting requirements. Perhaps most importantly, for the first time the issues of "adaptation" and "impact of response measures" have been clearly separated from each other, so that it might in the future be possible to discuss the former without the latter.

It should be noted that most of the above mentioned measures simply reaffirm previous COP decisions ${ }^{14}$. The only section of the Buenos Aires adaptation programme that is completely new requests the COP's Subsidiary Body for Scientific and Technological Advice (SBSTA) to "develop a structured five-year programme of work on the scientific, technical and socio-economic aspects of impacts, vulnerability and adaptation"15. An attempt by Saudi Arabia to also broaden this section to response measures failed in the final plenary session. Furthermore, the document calls for an overall assessment of adaptation activities conducted within the UNFCCC process at COP 14 in 2008.

13 Decision 5/CP.7, Implementation of Article 4, paragraph 8 and 9 of the Convention, FCCC/CP/2001/13/Add.1, 21 January 2002.

14 Ibid.

15 See footnote 11 above.

16 Decision 7/CP.7, Funding under the Convention, FCCC/CP/2001/13/Add.1, 21 January 2002.

17 Decision -/CP.10, Report of the Executive Board of the clean development mechanism. Guidance relating to the clean development mechanism, advance unedited version.
The financial mechanisms that intends to provide funding for the above-mentioned activities includes the Least Developed Countries Fund (LDCF) and the Special Climate Change Fund (SCCF). These were established at COP 7 in $2001^{16}$ but are not yet fully operational. The LDCF currently finances the preparation of National Adaptation Programmes of Action (NAPAs), but the demand by developing countries to finance other activities was not resolved at this COP. This decision was forwarded to SB 22. Similarly, a decision on new guidance to the SCCF has also been deferred. This was mainly due to the late agreement on the Buenos Aires adaptation programme, which sets the basis for the SCCF negotiations.

\section{Finalising CDM implementation}

The implementation of the Clean Development Mechanism (CDM) was hotly debated in Buenos Aires. India launched fierce attacks against the Executive Board of the CDM (CDM EB) for its work on ensuring that projects are truly „additional“, i.e. reduce emissions below those that would have happened in the absence of the project activity. These complaints were echoing those of business representatives who have been criticising the complexity of the process since it was adopted. In the end the work of the CDM EB was for the most part reaffirmed, but the additionality tool developed by the CDM EB will be reviewed before COP/MOP ${ }_{1}{ }^{17}$.

Delegates from developing countries and some non-governmental organisations were voicing other concerns throughout the conference. Many of the projects that are pending approval aim at reducing emissions of methane and hydro-fluorocarbons. These are potent greenhouse gases, and mitigation activities are thus able to generate a great amount of relatively cheap emissions reduction certificates. However, as it was claimed, these projects contribute little to the goal of the CDM to assist host countries in achieving sustainable development. Some delegations therefore demanded that projects in the energy and transport sectors be more strongly promoted. Additionally, projects so far tend to concentrate on countries that provide a good enabling environment, whereas less developed countries, in particular most African countries, have so far been left empty-handed. Those developing countries therefore repeatedly demanded some 
remedial action to ensure a geographically balanced distribution of projects and that the sustainable development goal of the CDM be emphasised.

In addition, the COP requested SBSTA to discuss how to deal with projects that might be in conflict with the objectives of other environmental treaties, aiming to take a decision at COP/MOP $1^{18}$. This debate was prompted by HFC-23 decomposition projects, which are perceived to be in conflict with the Montreal Protocol on Substances that Deplete the Ozone Layer. HFC-23 is a by-product of producing HFC-22, which is governed by the Montreal Protocol. Raising revenues by generating CERs through the incineration of HFC-23 would lower the production costs of HFC-22, possibly stimulating its production and consumption. This would in turn undermine the purpose of the Montreal Protocol. Moreover, although HFC-22 is not governed by the Kyoto Protocol, it is also a potent greenhouse gas with a global warming potential of 1700 (i.e. 1700 times the global warming potential of $\mathrm{CO}_{2}$ ).

The COP noted that the CDM EB has been overloaded and under-funded, and with the entry into force of the Kyoto Protocol the workload is expected to grow even further. The UNFCCC secretariat estimates that the CDM EB currently faces a shortfall of US-\$ 4.2 million for the biennium $2004-2005^{19}$ and the CDM EB has urgently called on the Parties to the Kyoto Protocol to raise more funds.

On a more consensual note, the COP finalised the special simplified modalities for small-scale afforestation and reforestation projects ${ }^{20}$. The last missing element of the CDM has thus been put into place. The threshold for these projects was set at 8000 t $\mathrm{CO}_{2}$ estimated sequestration per annum. The conference agreed to reduce costs by excluding these projects from the adaptation levy and by reducing administrative fees (although the exact amounts have not yet been decided). One and the same operational entity will be allowed to carry out validation, verification and certification. The COP requested the CDM EB to develop default factors for assessing the existing carbon stocks and for simplified baseline methodologies as well as simplified monitoring methodologies. No decision was taken on whether or not to allow unilateral CDM projects, i.e. projects that are developed without participation from an industrialised country.

\section{Other decisions}

Three years after the Parties agreed upon frameworks for capacity building in developing countries $^{21}$ and in countries with economies in transition $^{22}$ as part of the Marrakesh Accords (COP 7), the review of their implementation was finalised. The final decisions on capacity building confirm that the scope of capacity building needs, which are outlined in these frameworks, are still relevant and they list some key factors that could assist its further implementation ${ }^{23}$.

Another element of the Marrakesh Accords, namely the rules for accounting of land use, landuse change and forestry (LULUCF) activities under Article 3.3 and $3.4^{24}$, was implemented by a COP decision on good practice guidance for reporting in the national inventories ${ }^{25}$. Article 3.3 and 3.4 allow Parties to count net removals of $\mathrm{CO}_{2}$ from the atmosphere and its storage in biomass through LULUCF activities towards their Kyoto targets. The guidance adopted by COP 10 is based on the IPCC Good Practice Guidance ${ }^{26}$ and completes the requirements for the establishment of the national reporting on greenhouse gas emissions under the Kyoto Protocol.

\section{Ibid.}

19 Ibid

20 Decision -/CP.10, Simplified modalities and procedures for small-scale afforestation and reforestation project activities under the clean development mechanism in the first commitment period of the Kyoto Protocol and measures to facilitate their implementation, advance unedited version.

21 Decision 2/CP.7, Capacity building in developing countries (non-Annex I Parties), FCCC/CP/2001/13/Add.1, 21 January 2002.

22 Decision 3/CP.7, Capacity building in countries with economies in transition, FCCC/CP/2001/13/Add.1, 21 January 2002.

23 Decision -/CP.10, Capacity building in developing countries (non-Annex I countries), advance unedited version; Decision /CP.10, Capacity building in countries with economies in transition, advance unedited version.

24 Decision 11/CP.7, Land use, land-use change and forestry, FCCC/CP/2001/13/Add.1, 21 January 2002.

25 Decision -/CP.10, Good practice guidance for land use, land-use change and forestry activities under Article 3, paragraphs 3 and 4, of the Kyoto Protocol, advance unedited version.

26 IPCC, Good Practice Guidance for Land Use, Land-Use Change and Forestry, Kanagawa/Japan 2003. 
Finally, COP 10 adopted decisions ${ }^{27}$ on the review of greenhouse gas inventories ${ }^{28}$, on the reporting format for the different types of emissions certificates under the Kyoto Protocol ${ }^{29}$ and on the registry system to administer those emissions certificates ${ }^{30}$.

\section{Silver linings}

Despite the rather meagre official outcome, not all was deepest shadow at COP 10. First, observers noted some indications that COP 10 may have seen a movement away from the rather dominant role OPEC has played in the G-77 and China. Least developed countries have in the past neglected their own interests in order to maintain a unified position within the G-77 and China. However, at COP 10 the LDCs and a number of other developing countries showed a new assertiveness. For example, Quatar, which has the presidency of the G-77 this year, was taken to task by other countries for representing primarily OPEC interests while neglecting those of the LDCs and AOSIS. AOSIS delegates and even the Indonesian minister demanded not to mix up adaptation to climate change and "adaptation" to

27 A list of all COP decisions is available at: http://unfccc.int/ meetings/cop_10/items/2944.php.

28 Decision -/CP.10, Issues relating to the technical review of greenhouse gas inventories of Parties included in Annex I to the Convention and the implementation of Article 8 of the Kyoto Protocol, advance unedited version.

29 Decision -/CP.10, Standard electronic format for reporting Kyoto Protocol units, advance unedited version.

30 Decision -/CP.10, Issues relating to registry systems under Article 7, paragraph 4, of the Kyoto Protocol, advance unedited version.

31 Ministry of Science and Technology, Brazil`s Initial National Communication to the United Nations Framework Convention on Climate Change, Brasilia 2004.

32 The People's Republic of China, Initial National Communication on Climate Change. Executive Summary, Beijing, 2004.

33 Ministry of Environment and Forests / Government of India, India's Initial National Communication to the United Nations Framework Convention on Climate Change, New Delhi 2004.

34 Assembly Bill No. 1493, Pavley, further information available at: http://www.arb.ca.gov/cc/cc.htm.

35 Regional Greenhouse Gas Initiative (RGGI) by 9 Northeast and Mid-Atlantic States, further information available at: http://www.rggi.org; New South Wales Greenhouse Gas Abatement Scheme, further information available at: http://www.greenhousegas.nsw.gov.au.

36 Inuit Circumpolar Conference Executive Council Resolution 2003-O1, Re: Climate Change and Inuit Human Rights, 2003. See also Wagner/Goldberg, An Inuit Petition to the Inter-American Commission on Human Rights for Dangerous Impacts of Climate Change, Buenos Aires 2004. the impacts of response measures. In addition, developing countries showed different levels of support for the seminars. If this trend continues, opportunities for new alliances in favour of meaningful climate action might arise.

Another positive landmark was the presentation of the initial national communications of Brazil ${ }^{31}$ and China ${ }^{32}$, which provide detailed accounts of the magnitude and the sources of greenhouse gas emissions as well as policies and measures taken by both countries. The dominant source of emissions in Brazil derives from deforestation of its vast forests, whereas China's emissions stem mainly from the heavy use of coal for power generation and heating. Being the most populous country in the world and undergoing extremely rapid industrialisation, China's report on national emissions and climate policy is critical in understanding the state of the global climate. India had already submitted its initial national communication earlier in $2004^{33}$. The submission of these documents by three of the leading powers among the developing countries is a strong signal of their continuing commitment to the climate regime. It also signals a new alliance between these countries.

There are furthermore several developments outside of the UNFCCC process that provide some reason for greater optimism regarding climate policy in the United States. It is becoming increasingly obvious that the approach of the current administration does not represent a countrywide consensus on global warming and the same is true for Australia. Several side events reported that federal States in these countries as well as individual companies are increasingly taking climate policy into their own hands. For example, California has recently passed ambitious standards for vehicular emissions reductions ${ }^{34}$ and several states in the north-east of the US as well as some of the Australian states are embarking on regional emissions trading schemes ${ }^{35}$.

In yet another twist, the failure of the political process in the last remaining industrialised States outside the Kyoto Protocol encourages political actors to resort to the law courts. In the latest instance, the Inuit announced to file a petition with the Inter-American Commission on Human Rights against the United States, arguing that global warming violates their rights to life, residence, the inviolability of their homes, health and well-being ${ }^{36}$. The number of climate-related cases in court has thus 
increased to ten, covering seven countries in both the Northern and the Southern hemisphere. The Victorian Civil and Administrative Tribunal (Australia), for example, has ruled that an approval for the operation of a lignite coal power station is invalid if impacts of greenhouse gas emissions are not taken into account in the approval process ${ }^{37}$.

\section{Ways ahead}

The tenth Conference of the Parties in Buenos Aires was in a rather strange position: While only a few issues surrounding the Kyoto Protocol remained to be resolved before its first Meeting of the Parties, COP 10 had no mandate to discuss the future of the climate regime. The European Union in this situation supported the idea introduced by Ambassador Estrada, to organise two seminars in 2005 for the discussion of future directions - and opened a hot debate on the future process. The focus of the EU was thus not on celebrating the entry into force of the Protocol or the immediate challenges ahead, especially the implementation of the Kyoto Proto$\mathrm{col}$, but rather on the future of the regime after 2012.

The tendency to always focus on the challenges ahead of the problems at hand may reflect a general tendency of the EU and may well be deeply engrained in its collective psyche. This is clearly visible in its never-ending reform and enlargement process that aims at the next step before one stage has even been fully initiated. Whether applying this approach to the climate policy process is helpful, remains to be seen. The EU strategy at COP 10 certainly put the United States centre stage once again in a meeting that could have been much more positive and forward-looking. As a negative side effect, this strategy prevented the formation of a strategic alliance with countries like China, India and Brazil because it encouraged them to move into the camp of the United States and Saudi Arabia.

The EU is of course faced with a difficult situation, considering that the Kyoto Protocol is entering into force with no prospect of US participation in the near future. Additionally, the internal opposition to further action is mounting: The enactment of the EU emissions trading system woke up industry, lobbyists and economics ministries in all of its Member States, which are now putting immense pressure on the Commission and the Council not to move any further - at least not without the US and major State actors from the global South. From the other side, there is increasing pressure from scientists and the environmental movement not to stand still on Kyoto but instead to further expand its commitments. Seizing the opportunity presented by the seminars was thus understandable. The last-minute agreement on the seminar might even be considered a successful attempt to integrate the US in "talks about talks about talks" about the future framework of the regime.

Nevertheless, the real challenge for the immediate future lies in the implementation of the Kyoto Protocol. Making all the rules, mechanisms and institutions work will require immense personal and also financial investments, for example by increasing the funding for the CDM Executive Board to make it more effective. Moreover, the successful implementation of the first commitment period will determine whether the cap-and-trade approach taken in the Kyoto Protocol is viable and can thus serve as a model for the time after 2012. If the European Union has an interest in seeing more obligations of this kind in the future, this is where it should invest. This would appear to be a worthwhile investment, because there is a great likelihood that any future US administration willing to engage seriously in climate policy will opt for a capand-trade model. This is what the United States proposed for Kyoto, it is the approach chosen by the McCain/Liebermann bill ${ }^{38}$ and the Regional Greenhouse Gas Initiative of the north-eastern States in the US also builds on a power plant cap-and-trade system $^{39}$.

Consolidating the Kyoto architecture therefore will at the same time provide a framework for the future regime after 2012. Planning this future will start later this year: In 2005, industrialised countries are required to show "demonstrable progress" in achieving their commitments (Article 3.2 Kyoto Protocol) and they are furthermore requested to start "initiating the consideration" of future commitments for industrialised countries after 2012 (Article 3.9 Kyoto Protocol). The first COP/MOP of

\footnotetext{
37 VCAT, Judgment in Case No. P2257/2004, Australian Conservation Foundation v Minister for Planning [2004] VCAT 2029, 29 October 2004.

38 Bill Number S.139 for the 108th Congress, Climate Stewardship Act of 2003.

39 See footnote 35 above.
} 
the Kyoto Protocol will take place from 28 November to 9 December 2005 in Montreal, Canada, in conjunction with the COP of the FCCC. This body will have to initiate such considerations - not only in relation to commitments for industrialised countries, but also for some developing countries. Expanding commitments to at least some developing countries (and the US) will also be a most likely demand of the second COP/MOP, which has to review the Protocol in the light of the best available scientific information assessments on climate change and its impacts (Article 3.9 Kyoto Protocol).

One of the main challenges of these future negotiations is to refine the categories of countries in the climate regime beyond the rather crude differentiation into "Annex II", "Annex I" and "non-Annex I" countries. This means in particular to further differentiate between countries that have not yet adopted quantified mitigation commitments (nonAnnex I countries). This group of countries is too heterogeneous to be treated alike in future agreements on global mitigation efforts, since it comprises countries that are as different as Asian Tigers on the one hand and most African countries on the other. A recent proposal by 14 researchers, most of them from developing countries, addresses this issue by presenting an approach for differentiation among non-Annex I countries ${ }^{40}$. The "South-North" approach takes into account specific national circumstances of a country, like the potential and the capability to mitigate, as well as the responsibility for causing climate change. The proposal identifies four groups of countries and designates different types and levels of mitigation commitments for each of them. The groups of "Newly Industrialised Countries" (e.g. South Korea, Saudi Arabia) and "Rapidly Industrialising Countries" (e.g. China, Brazil) are envisaged to take on quantified emissions limitation and reduction commitments in the near future, which is in line with all scenarios aiming at less than $2^{\circ} \mathrm{C}$ warming compared to the

40 Ott/Winkler/Brouns et al., South-North Dialogue on Equity in the Greenhouse. A proposal towards an adequate and equitable global climate agreement, GTZ, 2004. See also:

http://www.south-north-dialogue.net. pre-industrial level. It should be noted, however, that these commitments are conditional on financial transfers from Annex I-countries to support required mitigation activities.

Nonetheless, before negotiations on the design of a future agreement can start, the forum for negotiations has to be agreed upon (COP or $\mathrm{COP} / \mathrm{MOP}$ ). Negotiating in the context of the COP/MOP of the Kyoto Protocol, as described above, has one disadvantage since it does not include the United States as a party but as an observer. There were considerations by some parties in Buenos Aires that the post-2012 negotiations should take place in the context of the FCCC in order to allow the full participation of the USA. This, however, could be interpreted as "abandoning" the Kyoto Protocol. Implementation and development of the flexible mechanisms would thus be impaired because of seemingly missing support for the Protocol.

It might therefore be advisable to combine the strengths of both treaties and create a forum for negotiations of the post-2012 phase that operates under the guidance of the COP of the FCCC as well as under the guidance of the COP/MOP of the Kyoto Protocol. In such a combined negotiating forum the US would be participating as a party, while the integrity of the Kyoto Protocol would be maintained. Negotiations could easily move to whatever forum will be agreed upon in the end. Large developing countries that are wary of taking on commitments before the North has shown leadership might also feel comfortable with this solution.

In the end it takes two to tango, as the saying goes. The European Union will have to decide whether to wait for an unwilling partner or whether to look for more promising dancers like China, India and Brazil in the meantime. COP 10 in Buenos Aires allowed a first exploration of ideas. The mounting impacts of climate change, pressure from industry and farmers as well as prospects of making business with the EU, Japan and China will in the end drive the United States back into the multilateral climate regime. History favours those with a long breath. The European Union as a new actor on the world stage still has to prove that it is able to strategically pursue its interests. 

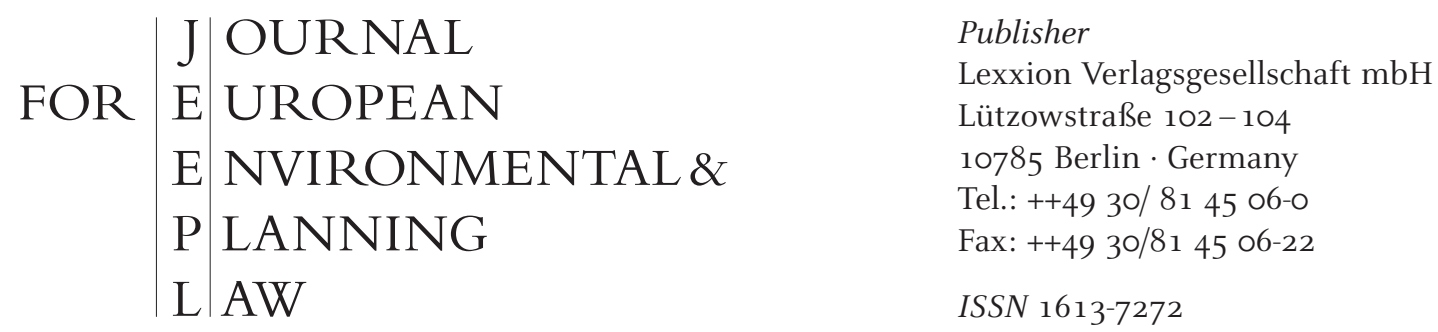